\title{
COMMUNITY BASED TOURISM DALAM PENGEMBANGAN KAMPUNG NELAYAN KEDUNG COWEK DI SURABAYA
}

\author{
Annisa Nur Ramadhani ${ }^{1}$ \\ Institut Teknologi Adhi Tama Surabaya \\ annisanur@itats.ac.id
}

\begin{abstract}
Abstrak
Paper ini berfokus pada analisa pengaturan permukiman nelayan dan eksplorasi konsep pembangunan pemukiman nelayan berkelanjutan. Tujuan dari penelitian ini adalah untuk mengembangkan pemukiman nelayan berkelanjutan berdasarkan konsep community based tourism. Penelitian ini dilakukan di kampung nelayan Kedung Cowek yang terletak di wilayah pesisir Surabaya. Mayoritas masyarakat kampung bekerja sebagai nelayan dan masih mempertahankan budaya dan kegiatan nelayan tradisional dalam gaya hidup lokal masyarakat. Kampung ini memiliki potensi besar untuk menjadi situs pariwisata berbasis CBT (Community Based Tourism). Namun, kondisi saat ini menunjukkan bahwa pemukiman nelayan di daerah ini tidak berkembang secara signifikan. Rekomendasi pengembangan di kampung nelayan Kedung Cowek ini harus memperhatikan budaya dan tradisi setempat dengan menerapkan unsur teknologi untuk pengembangannya. Dalam hal ini, dukungan peran berbagai stakeholder seperti pemerintah, akademisi, LSM, CSR, dan penduduk setempat sangat vital diperlukan untuk pengembangan kampung menuju kampung nelayan berbasis community based tourism. Hasil penelitian ini dapat digunakan sebagai masukan untuk perencanaan kota dan desain perkotaan wilayah pesisir Surabaya menuju konsep Pariwisata Berbasis Masyarakat.
\end{abstract}

Kata Kunci: Kampung Nelayan Berkelanjutan, Community Based Tourism, Sustainable Development

\begin{abstract}
This paper mainly focused on fisherman settlement setting's analysis and explore the development concept toward sustainable fisherman settlement. The purpose of the study was to develop sustainable fisherman settlement based on community based tourism concept. This research was conducted in fisherman settlement named Kampung Kedung Cowek which is located at the coastal area of Surabaya - the capital of East Java Province. The fisherman settlement located in coastal areas and has long existed in Surabaya. The majority of society work as fisherman and we could see almost all of traditional fisherman activity and local way of life there. The fisherman culture still be preserved there. This Kampung have a big potential to being tourism site based on CBT (Community Based Tourism). However, the reality indicates that the fisherman settlement in this area didn't well developed and the setting does not change significantly. Recommendations for the development in Kampung Kedung Cowek must pay attention to local culture and traditions by applying technological elements. In this case, the role support of various stakeholders such as the government, academics, NGOs, CSR, and the local population is necessary for implementing community based tourism development. The results of this study can be used as input for urban planning and urban design of Surabaya's coastal areas towards Community Based Tourism concept.
\end{abstract}

Key words: Sustainable Fisherman Settlement, Community Based Tourism, Sustainable Development

\section{PENDAHULUAN}

Indonesia adalah salah satu negara kepulauan terbesar di dunia dengan 17.504 pulau dan 5,8 juta $\mathrm{km}^{2}$ lautan (UNCLOS, 1982). Karena tipologinya sebagai negara kepulauan, Indonesia juga kaya akan daerah pesisir pantai serta biodiversitas flora dan fauna nya. Namun, potensi tersebut belum seluruhnya dikembangkan secara baik menjadi coastal tourism yang dapat berkontribusi memperbaiki perekonomian warga dan lingkungan binaan. Keterbatasan ini yang menyebabkan warga di daerah pesisir yang mayoritas adalah nelayan memiliki tingkat ekonomi rendah. Hal yang sama juga terjadi pada lingkungannya, dimana kampung nelayan di Indonesia mayoritas kumuh. (Fandeli, 2000). Di tahun 2012, jumlah permukiman nelayan mencapai 8090 permukiman, dan 1084 diantaranya merupakan kampung nelayan yang kondisinya tergolong kumuh, kotor, padat, dan penduduk dengan berpenghasilan rendah. Hal ini mengindikasikan kampung nelayan di Indonesia dapat berpotensi menjadi kantong-kantong kemiskinan (Kusnadi, 2006).

Surabaya merupakan salah satu kota dengan potensi pesisir yang besar, mulai dari daerah Gunung Anyar sampai Kenjeran. Menyadari potensi besar tersebut, Pemerintah Kota Surabaya memiliki program-program khusus untuk melakukan penataan ulang kawasan pesisir pantai Surabaya melalui pendekatan pariwisata pesisir. Bukan hanya wilayah pantai yang menjadi fokus pembangunan, namun juga permukiman nelayan yang dapat menjadi penunjang wisata. Salah satu prioritas daerahnya adalah kampung Kedung Cowek (surabaya.go.id, 2016). Namun belum semua bagian 
kampung merasakan dampak positif dari pembangunan tersebut. Salah satunya RW 3 Kampung Nambangan Perak, Kelurahan Kedung Cowek, Kecamatan Bulak, Surabaya.

Kondisi permukiman nelayan di kampung tersebut masih jauh dari kodisi ideal. Kondisi permukiman yang padat, kumuh, kotor, dan kurangnya public space menjadi permasalahan utama. Perekonomian warga pun tergolong lemah. Hal ini tidak sejalan dengan 4 pilar dalam sustainable development yang menjelaskan bahwa terdapat 4 faktor yang mempengaruhi yakni faktor lingkungan, ekonomi, sosial, dan budaya. Dimana permukiman seharusnya memiliki keseimbangan ekologis dari aspek lingkungan, keseimbangan sosial dan keadilan dari aspek sosial, material prosperity dari segi ekonomi, dan vitalitas budaya yang dapat dilihat dari keragaman dan social space yang tersedia di kampung (Hawkes,2011).

\section{RUMUSAN PERMASALAHAN}

Berbagai program perbaikan kampung nelayan yang telah dilaksanakan dapat menjadi salah satu alternatif yang berdampak baik pada perkembangan kampung nelayan di Indonesia. Integrasi kampung nelayan dengan Community-Based Tourism dapat menjadi solusi untuk menemukan konsep alternatif peluang penghasilan baru untuk para nelayan. Hal ini dapat menguntungkan nelayan secara ekonomi dan keberlanjutan lingkungan (Cahyadi,2012). Pendekatan partisipasi komunitas sudah lama dikemukakan dan menjadi salah satu aspek integral sustainable development. Partisipasi komunitas dapat meningkatkan kapasitas komunitas untuk mengurangi dampak negatif tourism development dan memperkuat kelebihannya. (Haywood, 1988; Jamal \& Getz,1995)

Paper ini akan mendiskusikan konsep pengembangan kampung nelayan berbasis community based tourism untuk mengembangkan potensi kampung nelayan di Indonesia sehingga dapat berkontribusi untuk memperbaiki lingkungan dan perekonomian warganya. Karena 2/3 warga Indonesia hidup di Kampung, dengan berbagai level standart, mayoritas adalah warga berpenghasilan menengah ke bawah (Setijanti,2006).

\section{Studi Kasus}

Wilayah studi yang dipilih adalah RW 3 Kampung Nambangan Perak, Kelurahan Kedung Cowek, Kecamatan Bulak, Surabaya. Wilayah ini dipilih karena pembangunannya tergolong masih tertinggal dibandingkan dengan wilayah Kedung Cowek lainnya yang telah mendapat program perbaikan dari Pemerintah Kota Surabaya.
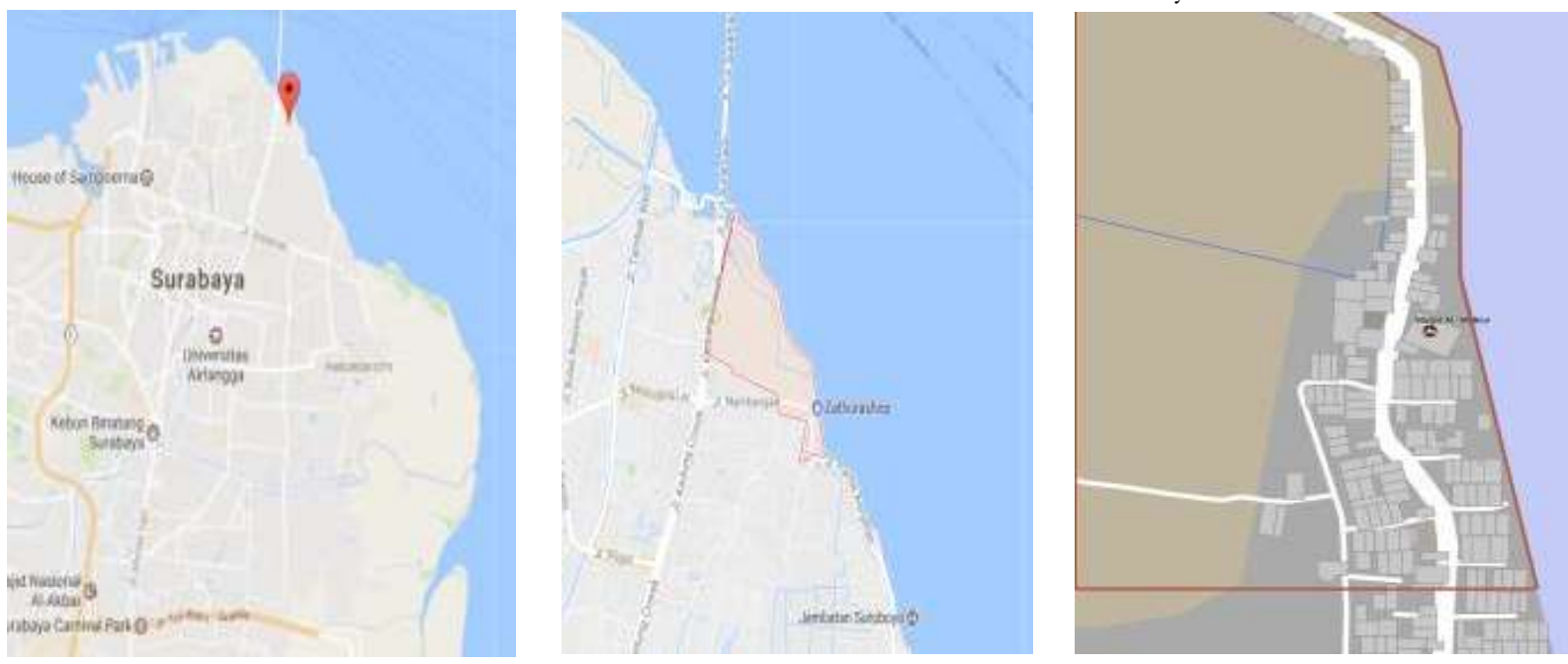

Gambar 1. Peta Kampung Kedung Cowek RW 3

(Sumber: Google Maps)

\section{METODE PENELITIAN}

Metode penelitian yang dipakai di paper ini adalah deskriptif kualitatif yang dilengkapi dengan elaborasi data. Sedangkan teknik pengumpulan datanya adalah observasi, kajian literatur dan in depth interview dengan ketua RW 3 Kampung Nambangan Perak, Kedung Cowek dan penduduk setempat. 


\section{LITERATURE REVIEW}

\section{Pembangunan Berkelanjutan dalam Konteks Global}

Sejarah pembangunan berkelanjutan diawali dari Conference on the Human Environment (Konferensi mengenai lingkungan manusia) yang diadakan oleh Perserikatan Bangsa - Bangsa (PBB) pada tahun 1972 di Stockholm. Dalam konferensi yang dihadiri oleh delegasi negara maju maupun negara berkembang termasuk Indonesia tersebut menghasilkan kesepakatan bahwa perlu adanya pertimbangan masalah lingkungan dalam program-program pembangunan yang selama ini dijalankan. Berangkat dari konferensi di Stockholm, PBB melalui World Conference on Environment and Development (WCED) pada tahun 1987 mempublikasikan sebuah laporan yang berjudul our comman future atau Brundtland report yang didalamnya memuat mengenai konsep pembangunan yang berkelanjutan. Menurut laporan tersebut pembangunan berkelanjutan didefinisikan sebagai proses pembangunan untuk memenuhi kebutuhan pada masa sekarang dengan tidak mengorbankan kemampuan generasi yang akan datang untuk memenuhi kebutuhannya. Sejak dipublikasikan oleh WCED mulai banyak para ahli dari berbagai disiplin ilmu mendefinisikan mengenai pembangunan berkelanjutan. Tidak berhenti sampai di pertemuan WCED, pembahasan mengenai pembangunan berkelanjutan dilanjutkan dengan United Nations' Earth Summit atau Konferensi Bumi PBB pada tahun 1992 di Rio Janerio yang menghasilkan Agenda 21 dan disambung dengan pertemuan di Johannesburg yang dilaksanakan Majelis Umum PBB yang mengadopsi Millenium Development Goals pada tahun 2000 dan Konferensi Tingkat Tinggi (KTT) Dunia pada tahun 2002. Dari berbagai pertemuan yang diadakan menunjukkan bahwa betapa pentingnya pembangunan berkelanjutan.

\section{Tiga Pilar Pembangunan Berkelanjutan}

Terdapat 3 pilar utama dalam sustainable development seperti pada diagram di samping (IUCN 2006) yang menjelaskan bahwa terdapat 3 faktor yang mempengaruhi sustainable development yakni faktor lingkungan, ekonomi, dan sosial. Dari tiga pilar tersebut, faktor lingkungan mencakup aspek layak (viable) dan dapat dipertahankan (bearable), faktor ekonomi mencakup aspek adil (equitable) dan layak (viable), sedangkan faktor sosial mencakup aspek bearable dan equitable.

\section{Empat Pilar Pembangunan Berkelanjutan}

Dalam Perkembangannya, tiga pilar pembangunan berkelanjutan dikembangkan menjadi 4 pilar pada the dan the United Cities and Local Governments (UCLG) pada tahun 2010, dimana terdapat satu variabel tambahan yakni faktor culture yang dipengaruhi budaya kontekstual lingkungan binaan. Hal ini menjadi lebih kompleks dimana faktor budaya sendiri mencakup beberapa aspek yani wellbeing, creativity, diversity dan innovation.

\section{New Urban Agenda}

New Urban Agenda merupakan cara untuk mengatur dan mengarahkan urbanisasi global agar dapat mencapai pembangunan berkelanjutan. New Urban Agenda itu penting karena mencakup beberapa hal yaitu :

- Mencakup lingkungan urbanisasi di semua tingkat pemukiman manusia

- Merupakan kebijakan yang lebih tepat untuk dapat meliputi keseluruhan lingkungan fisik urbanisasi. (menjembatani daerah perkotaan, pinggiran kota dan pedesaan)

- Dan membantu pemerintah dalam mengatasi tantangan melalui kerangka kebijakan pembangunan nasional dan daerah.

- Mengintegrasikan kesetaraan untuk agenda pembangunan. Kesetaraan menjadi masalah keadilan sosial, menjamin akses ke ruang publik, perluasan peluang dan meningkatkan kepentingan bersama.

- Mengedepankan perencanaan perkotaan nasional dan perluasan kota yang direncanakan.

- Memutuskan seberapa relevan tujuan pembangunan yang didukung melalui urbanisasi berkelanjutan.

- Menyelaraskan dan memperkuat pengaturan kelembagaan dengan hasil substantif Habitat III

\section{Sustainable Fisherman Settlement Development}

Dalam Fishermans Bend Urban Renewal Area Draft Vision and Interim Design Guidelines (Port Philip, 2013), terdapat 10 konsep strategi perkembangan permukiman nelayan:
1. The creation of 21 st century jobs
2. The timely provision of infrastructure
3. A place that is easy to get around
4. A vibrant, mix of uses and activities 
5. Distinctive and diverse neighborhoods

6. A great place for families

7. A bigh quality built environment

8. Smart environmental solutions

9. Environmental constraints addressed

10. Strong partnerships and effective governance.

\section{Konsep Pengembangan Community Based} Tourism

\section{a. Definisi Community Based Tourism}

Menurut Suansri 2003, Community Based Tourism merupakan pembangunan pariwisata yang mengedepankan aspek lingkungan, sosial, ekonomi, dan budaya. Pembangunan dikelola dan dimiliki oleh dan untuk kepentingan masyarakat/komunitas, dengan tujuan untuk menarik minat turis/wisatawan untuk ikut belajar bersama masyarakat dan merasakan local way of life.

\section{b. Aspek Community Based Tourism}

Menurut (Suansri 2003), aspek community based tourism antara lain:

1. Natural and Cultural Resources

- Natural resources are well preserved

- Local economy and modes of production depend on the sustainable use of natural resources

- Customs and culture are unique to the destination

2. Community Organizations

- The community shares consciousness, norms and ideology

- The community has elders who hold local traditional knowledge and wisdom

- The community has a sense of ownership and wants to participate in its own development

3. Management

- The community has rules and regulations for environmental, cultural, and tourism management

- A local organization or mechanism exists to manage tourism with the ability to link tourism and community development

- Benefits are fairly distributed to all

- A precentage of profits from tourism is contributed to a community fund for economic and social development of the community

4.Learning

Tourism activities and services aim at:
- Fostering a shared learning process between hosts and guests

- Educating and building understanding of diverse cultures and ways of life

- Raising awareness of natural and cultural conservation among tourist and the local community

Selain itu, Community Based Tourism juga bisa menjadi alat untuk mewujudkan Sustainable Development (Suansri 2003), yakni dengan breakdown sebagai berikut:

Tabel 1. Indikator Community Based Tourism

\begin{tabular}{ll}
\hline Dimensi & Indikator Community Based \\
Tourism
\end{tabular}

\begin{tabular}{|c|c|}
\hline Lingkungan & $\begin{array}{l}\text { - Studi kapasitas area } \\
\text { sebagai penunjang wisata } \\
\text { - Memanajemen waste } \\
\text { disposal atau limbah } \\
\text { - Memiliki social space atau } \\
\text { public space yang dapat } \\
\text { digunakan masyarakat } \\
\text { setempat maupun } \\
\text { wisatawan }\end{array}$ \\
\hline Sosial & $\begin{array}{l}\text { - Komunitas memiliki sense of } \\
\text { ownership dan mau } \\
\text { berpartisipasi dalam } \\
\text { pembangunan } \\
\text { - Membangun/memperkuat } \\
\text { organisasi masyarakat } \\
\text { - Komunitas memiliki tetua } \\
\text { yang memegang teguh } \\
\text { norma dan adat }\end{array}$ \\
\hline Ekonomi & $\begin{array}{l}\text { - Kegiatan ekonomi lokal } \\
\text { yang memanfaatkan potensi } \\
\text { alami daerah } \\
\text { - Meningkatkan pendapatan } \\
\text { masyarakat } \\
\text { - Menciptakan lapangan } \\
\text { pekerjaan baru melalui } \\
\text { tourism }\end{array}$ \\
\hline
\end{tabular}

\begin{tabular}{ll}
\hline Budaya & Memiliki budaya (local way \\
& of life) yang menarik sebagai \\
& destinasi wisata \\
- & Menghargai \\
& keanekaragaman budaya \\
- & Menanamkan \\
& pembangunan dalam \\
& budaya lokal
\end{tabular}

Sumber: Suansri (2003)

Hal ini juga selaras dengan pendapat Ramadhani (2017) dimana pengembangan sustainable tourism dapat 
diwujudkan dengan berdasarkan pada analisis lingkungan dan sosial budaya yang meliputi perbaikan lingkungan fisik; pemangku kepentingan kerja sama; memperkuat organisasi masyarakat dan pembentukan organisasi pariwisata; membangun ruang terbuka hijau, area parkir, papan nama, dan fasilitas pariwisata; itu peningkatan perusahaan berbasis rumah dan perusahaan local untuk mendukung kegiatan pariwisata; pembentukan pariwisata budaya khusus program; dan pemberdayaan masyarakat lokal melalui pelatihan dan pemantauan.

\section{HASIL DAN PEMBAHASAN}

Dari hasil observasi dan in depth interview dengan masyarakat pada area studi kasus, didapatkan beberapa analisis terkait dengan aspek sustainable development, antara lain sebagai berikut:

\section{Aspek Lingkungan}

Dari hasil observasi dan in depth interview, didapatkan data terkait analisa aspek lingkungan sebagai berikut:

Tabel 2. Analisa Kondisi Eksisting dan Rekomendasi pada Aspek Lingkungan

\begin{tabular}{ll}
\multicolumn{1}{c}{ Indikator } & \multicolumn{1}{c}{ Kondisi Eksisting } \\
\hline Studi & Studi Kapasitas Lingkungan \\
$\begin{array}{l}\text { Lapasitas } \\
\text { Lingkungan }\end{array}$ & a) $\quad \begin{array}{l}\text { Pola Tata Ruang Lingkungan } \\
\text { Lingkungan kampung nelayan terkesan padat dan kurang } \\
\text { tertata, hal ini disebabkan banyaknya penduduk yang mendiam } \\
\text { kampung nelayan kedung cowek. Polanya pun tidak teratur } \\
\text { sehingga menyebabkan kondisi permukiman terkesan kumuh. } \\
\text { Namun pola eksisting yang ada merupakan salah satu bentuk } \\
\text { keaslian budaya khas nelayan yang harus dipertahankan. Pola } \\
\text { permukiman yang ada di kampung ini memiliki nilai sejarah dan } \\
\text { kesesuaian dengan karakteristik nelayan Kedung Cowek. }\end{array}$
\end{tabular}

Gambar 2. Kondisi Pola Pemukiman
Dalam segi lingkungan, perlu adanya perbaikan kualitas rumah penduduk dengan pengecatan dan perbaikan struktur yang melibatkan partisipasi masyarakat. Atau berupa mural yang menggambarkan budaya nelayan di sekitar kampung. Hal ini akan menjadi salah satu faktor penarik wisatawan untuk berkunjung, terutama untuk fotografi.

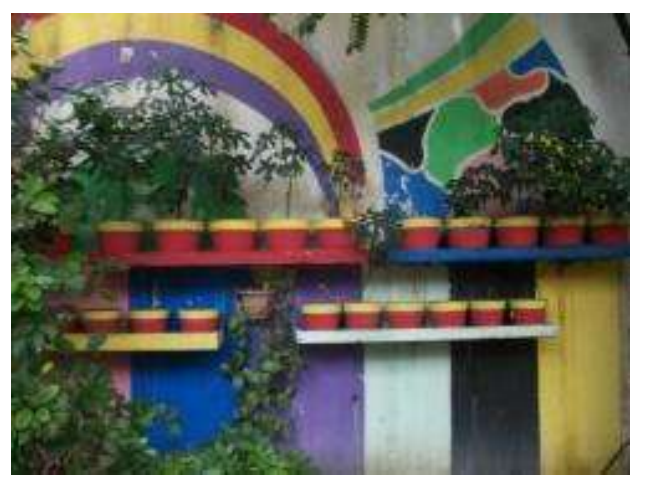

Gambar 3. Rekomendasi Perbaikan 
b) Aksesibilitas

Aksesibilitas cukup terjangkau karena terletak di area Pantai Kenjeran dan lokasi yang berdekatan dengan sentra ikan Bulak. Namun jalan yang ada kondisinya kurang layak, karena sudah rusak dan berlubuang. Perlu adanya perbaikan jalan dengan di aspal ataupun di paving

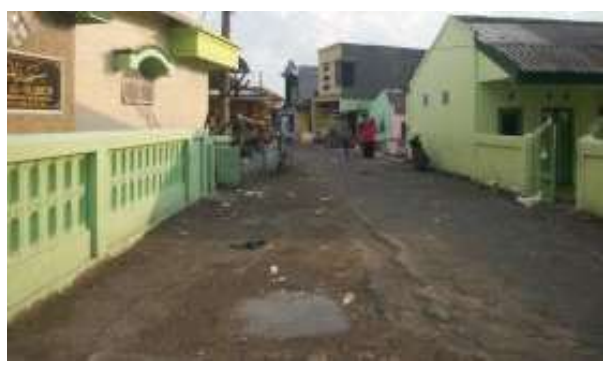

Gambar 4. Kondisi Jalan Pemukiman
Rekomendasi perbaikan kondisi jalan kampung, dimana kondisi eksisting yang masih berlubang dapat diperbaiki dengan diberi paving dan dilukis untuk menambah estetika

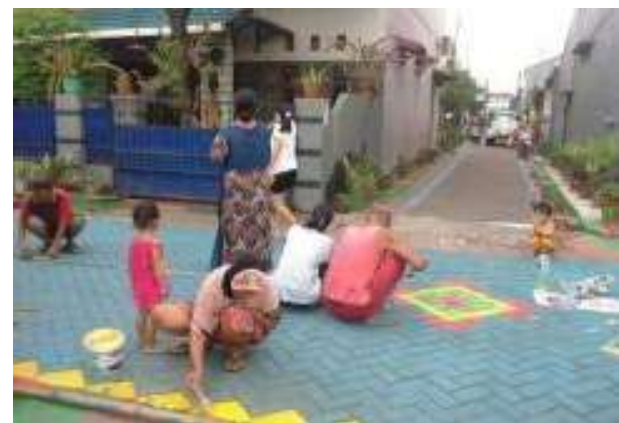

Gambar 5. Rekomendasi Paving c) Ketersediaan Infrastruktur

Infrastruktur jalan sudah cukup memadai, namun saluran air hujan masih tradisional dan belum ada perbaikan. Sebelumnya saluran ini masih bisa menampung debit air hujan dengan baik dan mengalirkannya langsung ke laut. Namun karena adanya pembangunan perumahan modern di sekitar kampung, menyebabkan terjadi banjir kiriman di kampung ini. Saluran drainase ini tidak dapat mengalirkan dengan baik debit air hujan kiriman berlebih.

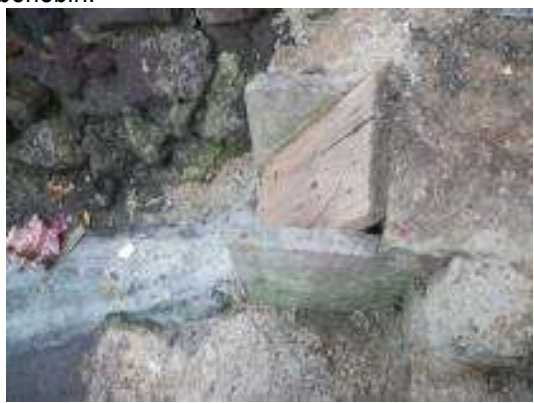

Gambar 6. Selokan eksisting yang tradisional
Rekomendasi perbaikan infrastruktur selokan agar dapat mengalirkan debit air hujan sehingga permukiman tidak banjir.

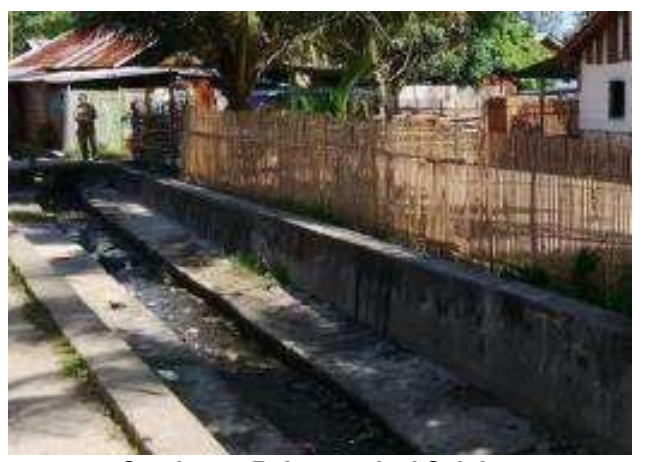

Gambar 7. Rekomendasi Selokan d) Tidak adanya Tempat Pembuangan Sampah (TPS) di area ini merupakan permasalahan utama yang terjadi. Hal ini menyebabkan banyak sampah yang berserakan di sekitar lingkungan. Mulai dari sampah anorganik yang terbawa arus ke tepi pantai sampai sampah hasil rumah tangga warga.
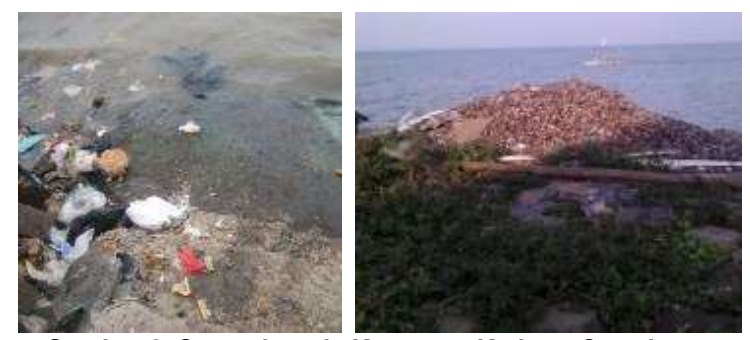

Gambar 8. Sampah pada Kampung Kedung Cowek
Pembuatan TPS (Tempat Pembuangan Sampah) akhir lokal untuk masyarakat.

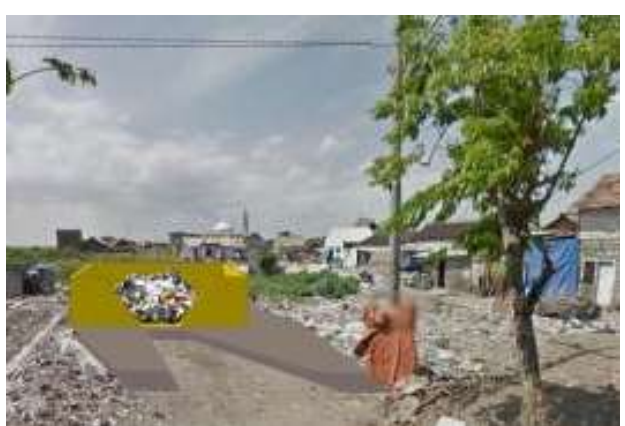

Gambar 9. Rekomendasi TPS Kampung 


\begin{abstract}
Manajemen
Water

Disposal

Dalam hal manajemen pengelolaan limbah, baik rumah tangga atau hasil tangkapan ikan, kampung ini masih kurang dalam implementasinya. Belum adanya teknologi seperti komposter, IPAL, dan semacamnya. Karena untuk kebutuhan primer yakni tempat pembuangan sampah saja masih belum ada. Pembangunan harus bertahap, dimana jika telah disediakan tempat pembuangan sampah, maka selanjutnya sampah sampah tersebut dapat diolah menjadi barang-barang yang lebih bermanfaat kedepannya
\end{abstract}

- Pembuatan saluran drainase baru untuk mencegah banjir kiriman

- Pembuatan sistem pengolahan air hujan

- Mengelola limbah kulit kerang menjadi barang atau bahan yang bermanfaat

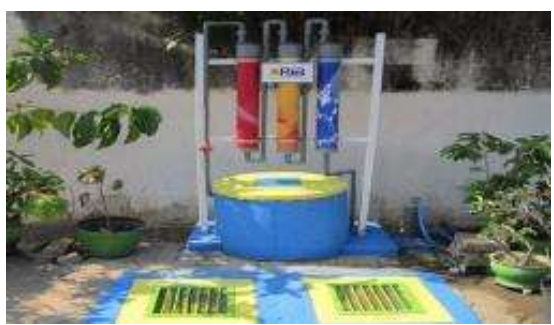

Gambar 10. Rekomendasi IPAL

\begin{tabular}{ll}
\hline Memiliki & Satu hal penting lain yang masih kurang dalam penyediaan sarana \\
social space & kampung adalah social space atau public space. Masyarakat \\
atau public & kampung belum memiliki social space sebagai tempat berkumpul dan \\
space yang & mengadakan kegiatan bersama, baik itu untuk nelayan dan ibu-ibu \\
dapat & dalam hal pengolahan ikan (mencuci, membersihkan, pengasapan, \\
digunakan & dan pengeringan) dan anak-anak yang kurang diwadahi tempat \\
masyarakat & bermainnya. \\
setempat & Kalau dulu sebelum terjadinya abrasi di pantai, social space terletak \\
maupun & di sepanjang pantai. Dimana anak-anak bisa bermain bola dan ibu- \\
wisatawan & ibu serta bapak-bapak dapat bersosialisasi sembari membersihkan \\
& ikan-ikan hasil tangkapan melaut.
\end{tabular}

Pembuatan public space atau social space secara partisipatif untuk kegiatan sosial warga dan wisatawan.
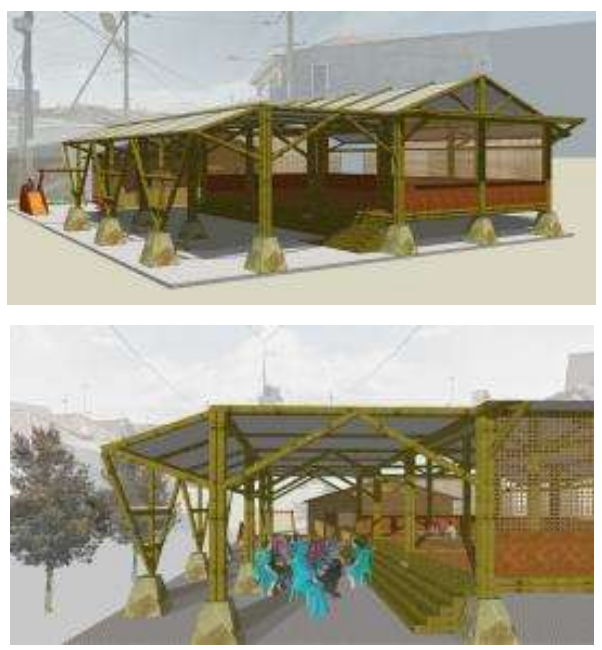

Gambar 11. Rekomendasi Desain Balai Warga

Sumber: Penulis (2019)

\section{Aspek Sosial}

Dari hasil observasi dan in depth interview, didapatkan data terkait analisa aspek sosial sebagai berikut:

Tabel 3. Analisa Kondisi Eksisting dan Rekomendasi pada Aspek Sosial

\begin{tabular}{|c|c|c|}
\hline Indikator & Kondisi Eksisting & Rekomendasi \\
\hline $\begin{array}{ll}\text { Sense } & \text { of } \\
\text { Ownership } & \\
\text { Masyarakat }\end{array}$ & $\begin{array}{l}\text { Kedung Cowek memiliki } 3613 \text { jiwa yang } 677 \text { jiwa diantaranya adalah } \\
\text { nelayan. Dan RW } 3 \text {, adalah wilayah yang prosentasi nelayannya paling } \\
\text { besar dari wilayah lain. Mayoritas pekerjaan warga adalah nelayan. }\end{array}$ & $\begin{array}{l}\text { Meningkatkan sense of ownership dengan } \\
\text { memperbanyak program bersama warga } \\
\text { seperti kerja bakti, senam pagi, dan lainnya }\end{array}$ \\
\hline
\end{tabular}

Hal ini disebabkan karena RW 3 berbatasan langsung dengan laut.

Aktifitas nelayan yang terjadi di kampung ini juga masih terjaga.

Sehingga ada keterikatan budaya dan mata pencaharian dari masyarakatnya. Hal ini tentunya mempengaruhi sense of ownership dari masyarakatnya, walaupun belum maksimal karena terkadang warga sudah terlalu sibuk dengan kegiatan nelayan sepanjang harinya, sehingga kurang dapat bekerjasama dalam program-program tertentu. 


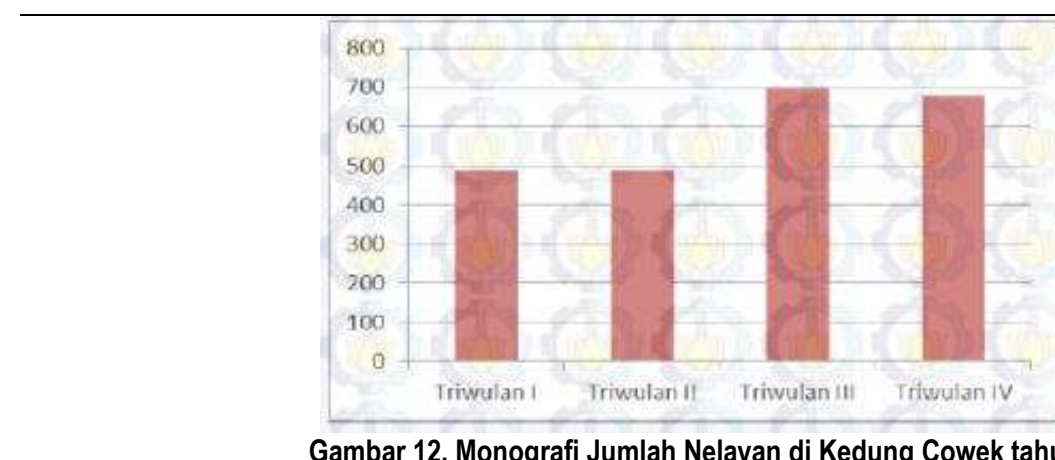

Gambar 12. Monografi Jumlah Nelayan di Kedung Cowek tahun 2013

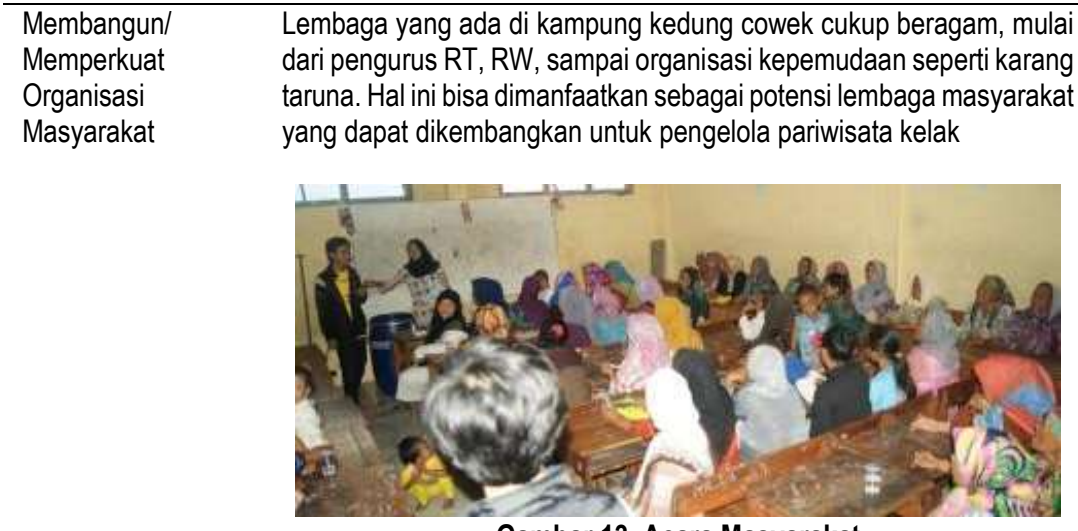

Gambar 13. Acara Masyarakat

Meningkatkan kapasitas lembaga
masyarakat yang ada

\begin{tabular}{lrll}
\hline Komunitas Memiliki & Komunitas memiliki ketua RW yang dianggap tetua di kampung ini. & Tetua menjaga tradisi dan harus selalu \\
Tetua & yang & Ketua RW ini merupakan penduduk asli kampung sejak dia lahir, dan & dilibatkan dalam merumuskan konsep \\
Berpegang & Teguh & paham betul tentang kondisi dan sejarah kampung. & pembangunan kampung
\end{tabular}

Menjaga

Kampung

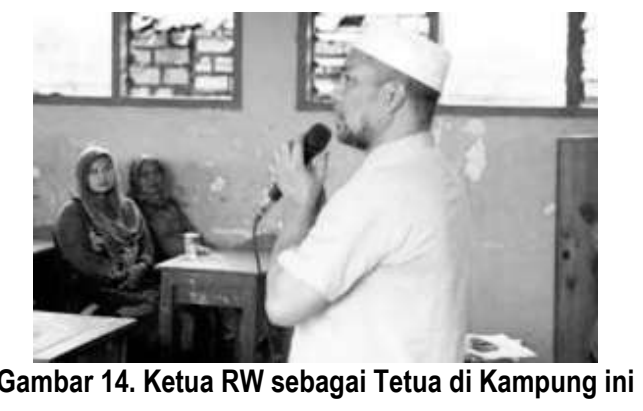

Sumber: Penulis (2019)

\section{Aspek Ekonomi}

Dari hasil observasi dan in depth interview, didapatkan data terkait analisa aspek ekonomi sebagai berikut:

Tabel 3. Analisa Kondisi Eksisting dan Rekomendasi pada Aspek Ekonomi

\begin{tabular}{|c|c|c|}
\hline Indikator & Kondisi Eksisting & Rekomendasi \\
\hline $\begin{array}{l}\text { Kegiatan Ekonomi } \\
\text { Lokal } \quad \text { yang } \\
\text { Memanfaatkan } \\
\text { Potensi Daerah }\end{array}$ & $\begin{array}{l}\text { Karena mayoritas warga adalah nelayan, kegiatan ekonomi } \\
\text { masyarakat kampung ini cenderung homogen. Kegiatan melaut } \\
\text { setiap hari terjadi di kampung ini, mulai dari melaut dan mencari ikan, } \\
\text { mencuci dan membersihkan ikan, pengasapan, pengeringan, sampai } \\
\text { pengolahan ikan. } \\
\text { Namun yang disayangkan adalah, kegiatan pengolahan tidak bisa } \\
\text { bersaing dengan wilayah luar bahkan Kelurahan Sukolilo dikarenakan } \\
\text { kurangnya sarana prasarana pengelolahan ikan yang baik kurangnya }\end{array}$ & $\begin{array}{l}\text { Peningkatan kualitas teknologi } \\
\text { (namun yang tradisional } \\
\text { dipertahankan betap } \\
\text { pendukung fator budaya) }\end{array}$ \\
\hline
\end{tabular}


sarana prasarana dalam mengelola hasil laut secara higienis, pengolahan,pengasapan ikan masih tradisional.

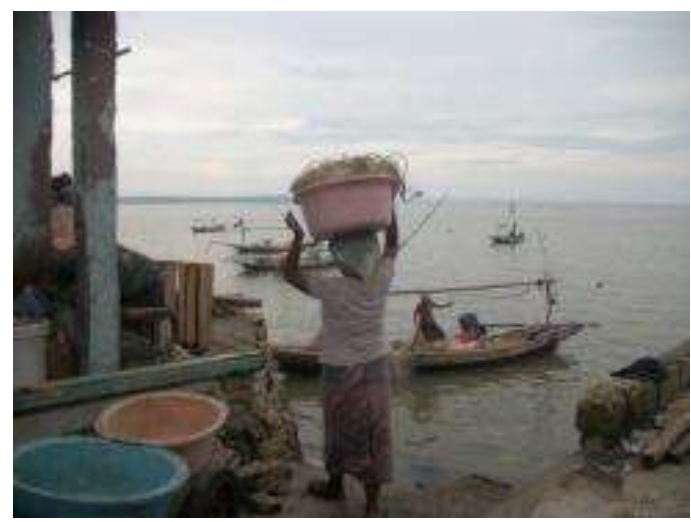

Gambar 15. Kegiatan Nelayan di Kampung ini

\begin{tabular}{|c|c|c|}
\hline $\begin{array}{l}\text { Meningkatkan } \\
\text { Pendapatan } \quad \& \\
\text { Menciptakan } \\
\text { Lapangan Kerja Baru } \\
\text { bagi Masyarakat }\end{array}$ & $\begin{array}{l}\text { Apabila kedepannya kampung ini dikembangkan sebagai area wisata } \\
\text { edukasi nelayan, tentunya akan berdampak pada peningkatan } \\
\text { pendapatan masyarakat setempat. Mengingat pendapatan } \\
\text { masyarakat yang masih dibawah UMR, yakni sebagai berikut: }\end{array}$ & $\begin{array}{l}\text { Pembangunan wisata edukasi kampung } \\
\text { nelayan yang dapat meningkatkan } \\
\text { pendapatan dan lapang pekerjaan baru } \\
\text { bagi masyrakat. }\end{array}$ \\
\hline
\end{tabular}

Sumber: Penulis (2019)

\section{Aspek Budaya}

Dari hasil observasi dan in depth interview, didapatkan data terkait analisa aspek budaya sebagai berikut:

Tabel 4. Analisa Kondisi Eksisting dan Rekomendasi pada Aspek Budaya

\begin{tabular}{|c|c|c|}
\hline Indikator & Kondisi Eksisting & Rekomendasi \\
\hline $\begin{array}{l}\text { Memiliki budaya lokal } \\
\text { (local way of life) yang } \\
\text { menarik sebagai } \\
\text { destinasi wisata }\end{array}$ & $\begin{array}{l}\text { Budaya lokal yang masih terjaga di lingkungan kampung adalah } \\
\text { budaya aktifitas nelayan. Hal ini terjjadi karena mayoritas warga RW } \\
3 \text { ini bermatapencaharian sebagai nelayan. Kegiatan yang dapat } \\
\text { disaksikan di kampung ini antara lain: } \\
\text { 1. Kegiatan Melaut }\end{array}$ & $\begin{array}{l}\text { Pengembangan kawasan wisata edukasi } \\
\text { kampung nelayan berbasis aktifitas } \\
\text { nelayang yang ada. Karena kampung } \\
\text { kedung cowek RW } 3 \text { ini sangat } \\
\text { berpotensi sebagai representasi } \\
\text { kehidupan nelayan tradisional Surabaya. } \\
\text { Dan nantinya wisatawan diajak untuk } \\
\text { merasakan langsung menjadi nelayan } \\
\text { dengan mengikuti kegiatan yang ada, } \\
\text { yakni melaut, membersihkan ikan, } \\
\text { pengasapan ikan, pengeringan, sampai } \\
\text { pengolahan ikan. }\end{array}$ \\
\hline
\end{tabular}

2. Kegiatan Pembersihan Ikan 


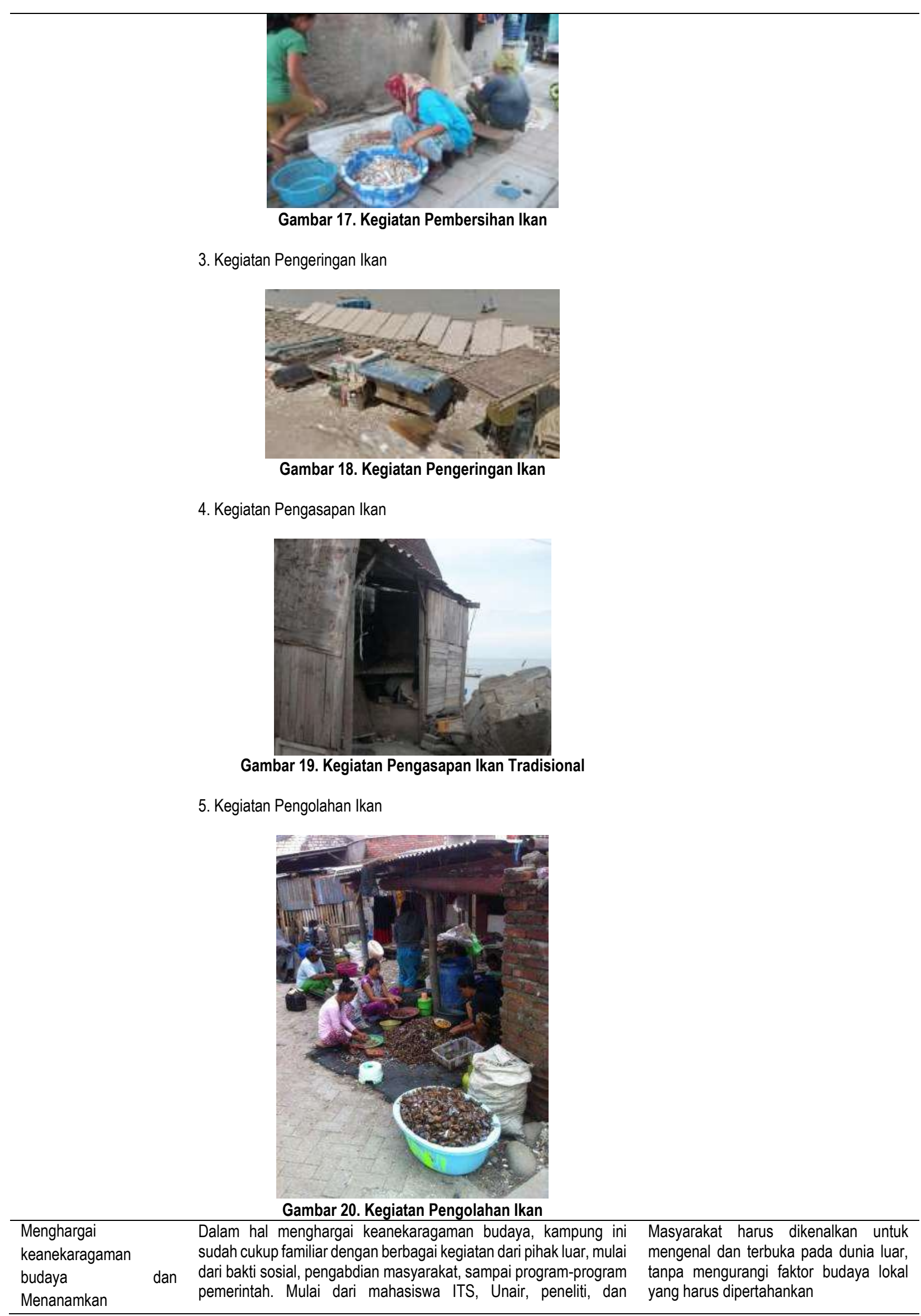




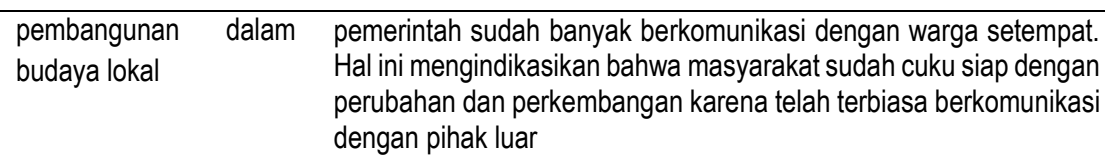

Sumber: Penulis (2019)

\section{KESIMPULAN}

Kampung Kedung Cowek merupakan salah satu kampung yang memiliki potensi besar dalam pengembangan wisata edukasi budaya kampung nelayan berbasis community based tourism. Di kampung Kedung Cowek ini, mayoritas masyarakatnya bermata pencaharian sebagai nelayan. Aktifitas budaya nelayan mulai dari melaut, pembersihan ikan, pengeringan, pengasapan, dan pengolahan ikan masih terjaga di Kampung ini. Sehingga kampung nelayan Kedung Cowek ini memiliki potensi yang besar untuk dikembangkan sebagai salah satu area wisata berbasis edukasi budaya dan aktifitas nelayan.

Namun dengan banyaknya potensi di atas, kondisi di lapangan masih sangat jauh dari kondisi ideal sebuah sustainable development. Banyak aspek mulai dari kurangnya kualitas lingkungan binaan, sosial, tingkat ekonomi yang masih rendah, sampai faktor budaya yang masih belum dikembangkan secara maksimal. Rekomendasi pengembangan di kampung nelayan Kedung Cowek ini harus memperhatikan budaya dan tradisi setempat dengan menerapkan unsur teknologi untuk pengembangannya. Dalam hal ini, dukungan peran berbagai stakeholder seperti pemerintah, akademisi, LSM, CSR, dan penduduk setempat sangat vital diperlukan untuk pengembangan kampung menuju kampung nelayan berbasis community based tourism.

\section{REFERENCES}

Cahyadi, R. 2012. Nelayan dan Pertarungan terhadap Sumber Daya Laut. Jurnal Kependudukan Indonesia. Vol 7 No 2 Page: 127-145

D. Getz, T. Jamal. 1995. Collaboration theory and community tourism planning. Journal Annals of Tourism Research. Volume 22, Issue 1, 1995, Pages 186-204.

Fandeli, C. dan Mukhlison. 2000. Pengusahaan Ekowisata.UGM.Yogyakarta.

Haywood-Farmer, J. (1988), "A Conceptual Model of Service Quality", International Journal of Operations \& Production Management, Vol. 8 No. 6, pp. 19-29.
Kusnadi, (2006). Filosofi Pemberdayaan Masyarakat Pesisir. Bandug: Humaniora.

P Setijanti. 2, 2006. Maritime Living Museum: Eksplorasi Ruang Ekspose Pesisir. U Syafrudin, P Setijanti. Jurnal Sains dan Seni ITS 6 (2), G407-G411, 2017.

Port Philip. 2013. Fishermans Bend Urban Renewal Area Draft Vision and Interim Design Guidelines. Melbourne: City of Port Phillip Submission.

Ramadhani, A.N. 2017. Development Concept Of Urban Housing Renewal Based On Sustainable Tourism: A Case Study Of Kampung Tambak Bayan, Surabaya. International journal of scientific \& technology research. Volume 6, issue 06, june 2017, pp 266-274. ISSN 2277-8616.

Suansri, P. 2003. Community Based Tourism Handbook. Thailand: Rest Project. ISBN : 974-91433-7-X 